\title{
Protective IMMUNITY AGAINST MALARIA LIVER STAGE AFTER VACCINATION WITH LIVE PARASITES
}

\author{
RÉNIA L.*
}

\section{Summary:}

Despite nearly 100 years of research and control efforts, malaria remains one of the most important infectious diseases. An efficient vaccine would be a powerful to tool to reduce mortality and morbidity. Experimentally, induction of sterile immunity in humans after vaccination with attenuated sporozoites has been obtained. This observation has spurred the search for subunit vaccines that aim to reproduce this protection. As yet none of the current candidate subunit vaccines achieved complete protection reproducibly. This failure coupled to the recent advent of genetically modified Plasmodium parasites has led to a renewed interest in the use of live parasites for vaccination against malaria pre-erythrocytic stages. In this article, we review and discuss the recent developments in this field.

KEY WORDS : malaria, vaccine, live parasite.

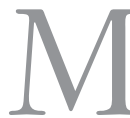
alaria remains one the deadliest diseases together with HIV and tuberculosis. Every year 200-500 million cases are recorded and some of them lead to one to 3 millions, mainly children in Africa (Brown, 2007). Although malaria is a major health problem in many tropical and sub-tropical countries, 20-50,000 cases of imported malaria also occur every year (Legros et al., 2007). Although the advent of DDT and chloroquine led to the belief that eradication was possible, the spread of parasites and insects resistant to the drugs and insecticides, has led to a resurgence of the parasite in economically disadvantaged countries (Molyneux, 2006). This worsening situation has called for the development of new control measures, of which vaccines have been a priority since the late 1970s. However, up to now, no vaccine formulation with sufficient efficacy against the malaria parasite has been developed (Renia et al., 2006). Reasons for these failure lie in part from the fact that the Plasmodium, the protozoan parasite responsible for the malaria, is a complex organism.

It life cycle involves two hosts, the insect vector and the intermediate mammalian host. The infection is ini-

\footnotetext{
* Laboratory of Malaria Immunobiology, Singapore Immunolog Network, AFSTAR (Agency for Science, Technology and Research), Immunos, Singapore 138673, Singapore.

Tel.: +33 (0)1 40516507 - Fax: +33 (0)1 40516535.

E-mail: renia_laurent@immunol.a-star.edu.sg
}

tiated with the inoculation of sporozoites by the mosquito in the skin, from where they travel via the blood stream to the liver. The parasite undergoes an obligatory multiplicative stage in hepatocytes. These steps are known as the pre-erythrocytic (PE) stages and generally are completed within a few weeks. The resulting daughter cells, the merozoites, then invade red blood cells, where they multiply predominantly asexually every 24, 48 or 72 hours depending on the species. At various times during this phase, male and female gametocytes are generated, and if these are ingested by a mosquito, fertilisation occurs and the mosquito eventually becomes infective to another vertebrate host. The mosquito and tissue stages are relatively short, while the cyclical multiplication in the blood is by far the longest phase of the life cycle. The parasite adopts highly characteristic forms at the different stages, where overlapping and distinct repertoires of genes are expressed, as an adaptation to the different environment in which they have to survive.

\section{THE PRE-ERYTHROCYTIC PARASITE: AN IDEAL TARGET}

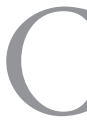
ompared to the other stages, the pre-erythrocytic stage represents an interesting target for malaria vaccine development. This phase of parasite development is asymptomatic and usually last two to 15 days depending on the malaria species. Moreover, in natural infection, very few sporozoites (5-50) (Rosenberg, 1992) are injected and further developed in hepatocytes. Thus, preventing sporozoites penetration into hepatocytes or destroying infected hepatocytes would prevent blood infection and the resulting pathology. We review here the different approaches using whole parasites which have been shown to be effective against pre-erythrocytic stage.

\section{THE GOLD STANDARD OF MALARIA PRE-ERYTHROCYTIC} STAGE PROTECTION: IRRADIATED SPOROZOITES

Use of radiation-attenuated sporozoites as vaccine was pioneered by Russell et al. (1942) using UV-attenuated 
avian malaria sporozoites. They were able to induce sterile protection in chickens against a sporozoite challenge. This data were extended to mammalian malaria in rodent, monkey and human malaria (reviewed in Nussenzweig, 1981). In the $P$. berghei/mouse model, protection was only obtained after intravenous inoculations or irradiated mosquito bites (Spitalny \& Nussenzweig, 1972; Kramer and Vanderberg, 1975). In studies using a limited number of human volunteers, repeated inoculations through mosquito bites with a total of at least a thousand irradiated infected mosquitoes were required to induce protection (Hoffman et al., 2002). However, large-scale generation of irradiated sporozoites was discarded for mass production since rearing and infection of millions of mosquitoes, combined with delivery issues, repeated inoculations with 1,000 or more irradiated mosquitoes were major limitations of this approach. However, workers at Sanaria Inc. (Luke et al., 2003) re-invented this approach. They have developed protocols for mass rearing and infections of mosquitoes under axenic conditions. Large numbers of sporozoites are now generated and human clinical trials with $P$. falciparum sporozoites are planned.

Although the irradiated sporozoites are the form inoculated by the mosquito, the induction of protective responses depends on the presence of viable and developmentally arrested liver stage parasites, generally as trophozoites or very early schizonts (Mellouk et al., 1990; Suhrbier et al., 1990, Scheller et al., 1995; Silvie et al., 2002). Over-irradiation (20,000 rads instead of $12-15,000$ rads) or inactivation by heat or paraformaldehyde treatment did not induce protection (Spitalny \& Nussenzweig, 1972: Mellouk et al., 1990). In addition, intrasplenic immunization with a low number of viable hepatocytes infected with irradiated sporozoites induced protection (Renia et al., 1994). Maintenance of protection also depends on the presence of irradiated sporozoites in the liver since primaquine treatment which eliminates the intrahepatic parasite abrogates protection (Scheller et al.,, 1995). The mechanisms of protection have been principally unveiled in the mouse model and have revealed a high degree of complexity. Antibodies, $\mathrm{CD}^{+}$and $\mathrm{CD}^{+}{ }^{+} \mathrm{T}$ cells, IFN- $\gamma$ and nitric oxide were found to be involved in various degrees depending on the parasite/host combinations (Druilhe et al., 1998; Doolan \& Hoffman, 2000). The immunity induced is strictly stage-specific since immunised mice remain fully susceptible to infected red blood cells (Nussenzweig et al., 1969), and it was considered that the same applies to immunised humans.

\section{GENETICALLY ALTERED SPOROZOITES}

The most exciting and promising recent advances has been made possible by the advent of routine genetic manipulation of Plasmodium together with the sequencing of the malaria parasite genome (Gardner et al., 2002; Carlton et al., 2002, Hall et al.; 2005), transcriptomic (Kappe et al., 2001; Kaiser et al., 2004; Hall et al., 2005), and proteomic analyses (Florens et al., 2002, Hall et al., 2005). In a series of elegant studies, a number of genes expressed by the sporozoite in the developing liver stages have been identified). Inactivation of the genes coding for the proteins IUS3, IUS4, or P36p, P52 and P36 (Mueller et al., 2005a, 2005b; Van Dijk et al., 2005; Labaied et al., 2007; Jobe et al., 2007) in $P$. berghei or $P$. yoelii resulted in parasites that could not complete liver stage development. These genetically altered sporozoites were recognised to reproduce the phenotype of irradiated sporozoites. Mice immunised intravenously with the different genetically altered sporozoites were fully protected against a challenge with normal sporozoites. In contrast to irradiated sporozoites, p36-deficient sporozoites could induce protection even after immunisation intramuscularly, subcutaneously or intradermally (Douradinha et al., 2007). Recent studies using the $P$. yoelii and the $P$. berghei models have shown that the protection was mediated by CD8 ${ }^{+} \mathrm{T}$ cells (Mueller et al., 2007; Tarun et al., 2007) and IFN- $\gamma$ (Mueller et al, 2007). Depending on the deficient $P$. yoelii parasite (UIS3- or UIS4-), intrahepatic persistence was not necessary for maintenance of protection (Mueller et al., 2007; Tarun et al., 2007, Jobe et al., 2007). Interestingly, immunisation with $P$. berghei p36- induced a cross-sterile protection against $P$. yoelii (Douradinha et al., 2007).

One potential major limitation of this approach is the possible occurrence of breakthrough infections. This has been observed for the IUS-4- and the p36- sporozoites (Mueller et al., 2005; van Dijk et al., 2005). To circumvent this problem, deficient parasites for two antigens UIS3 and UIS4 (Jobe et al., 2007) or P52 and P36 (Labaied et al., 2007) have been created and displayed no such events. These parasites were also very effective in inducing sterile protection.

\section{LIVE SPOROZOITE IMMUNIZATION UNDER CHLOROQUINE TREATMENT}

In the rodent malaria model, experiments have been performed to assess the effects of immunisation with normal sporozoites (Beaudoin et al., 1977; Orjih et al., 1982). An anti-malarial drug, chloroquine, capable of suppressing the blood stage of the infection but not the development of the PE parasite was used to ensure that immune responses were mainly directed against the PE stages. Under these conditions, single or multiple immunisations with normal sporozoites were shown to confer sterile protection. (Belnoue et al., 2004). Protection was shown to mainly depend on both $\mathrm{CD} 4^{+}$ and $\mathrm{CD}^{+} \mathrm{T}$ cells. As for the protection induced by 
immunisation with irradiated sporozoites, protection was dependent on the presence of liver parasites since treatment with primaquine, a drug that eliminates hepatic parasites, during immunisation abrogated the acquisition of protection. Interestingly, protection was directed not only against the liver stages but also against the blood stage parasites. This is one of the first demonstrations of the experimental induction of crossstage immunity. One of the main reasons as to these differences with irradiated sporozoite-induced immune responses is that the host would have been exposed to a much wider (and more natural) liver stage antigenic repertoire through natural infections than through the arrested hepatic forms resulting from irradiated sporozoite or genetically deficient parasite inoculation.

Preliminary experiments indicate that vaccination with one line of $P$. yoelii confers sterile protection against challenge with a different line, though not against another species such as $P$. berghei (unpublished observations). Indirect epidemiological observations have suggested that this approach might be effective in humans. Nigerian children followed-up over six months after cessation of a period of one to two years under chloroquine prophylaxis, revealed that the prevalence of $P$. falciparum and $P$. malariae were substantially reduced as compared to that in control "untreated" children (Bradley Moore et al., 1985).

\section{CONCLUSIONS}

T he main objective for a malaria pre-erythrocytic vaccine is ideally to prevent infection. 25 years after the identification of the first pre-erythrocytic antigen, the parasite still eludes all efforts to eliminate it by immunisation with sub-unit vaccines. Of many sub-unit formulations tested so far, only one, the RTS, S, a hybrid recombinant antigen coding for the Hepatitis B S antigen and a large fragment of the circumsporozoite protein, has shown limited efficacy (Alonso et al., 2004; Snounou et al., 2005). This relative failure of the subunit vaccine approach is in part due to a lack of sufficient knowledge of the immune mechanisms that are effective against Plasmodium, and the parasite antigens involved in protection. Vaccine development has thus been conducted in a rather semi-empirical manner and without the benefit of accepted immune correlates of protection that would have helped to improve experimental formulations. The availability of the genome sequences and the possibility to generate genetically manipulated parasites will undoubtedly help in identifying numerous new potential vaccine candidates. However, selecting those that will be appropriate to incorporate in a vaccine would still require major advances in fundamental knowledge of the biology, and the immunology of malaria pre-erythrocytic stages.

To date, the use of whole live parasites, attenuated or normal, not only offers the only means to induce sterile protection, but also provides the opportunity to obtain invaluable materials to dissect effective immune mechanisms.

\section{ACKNOWLEDGEMENTS}

T $\mathrm{R}$ is supported by the Singapore Immunology Network of A*STAR (Agency for Science, Technology and Research), Singapore. I deeply thank Lisa Fong Poh Ng for critical reading and English editing of the manuscript.

\section{REFERENCES}

Alonso P.L., Sacarlal J., Aponte J.J., Leach A., Macete E., Milman J., Mandomando I., Spiessens B., Guinovart C., Espasa M., Bassat Q., Aide P., Ofori-Anyinam O., Navia M.M., Corachan S., Ceuppens M., Dubois M.C., Demoitie M.A., Dubovsky F., Menendez C., Tornieporth N., Ballou W.R., Thompson R. \& COHEN J.D. Efficacy of the RTS,S/AS02A vaccine against Plasmodium falciparum infection and disease in young African children: randomised controlled trial. Lancet, 2004, 364, 1411-1420.

Bradley-Moore A.M., Greenwood B.M., Bradley A.K., Bartlett A., Voller A., Kirkwood B.R. \& Gilles H.M. Malaria chemoprophylaxis with chloroquine in young Nigerian children I. Its effect on mortality, morbidity and the prevalence of malaria. Annals of Tropical Medicine and Parasitology, 1985, 79, 549-562.

Brown H. Making malaria deaths easier to count. Bulletin of the World Health Organization, 2007, 85, 251-252.

Beaudoin R.L., Strome C.P.A., Mitchell F. \& Tubergen T.A. Plasmodium berghei: immunization of mice against the ANKA strain using the unaltered sporozoites as antigens. Experimental Parasitology, 1977, 42, 1-5.

Carlton J.M.R., Angiuoli S.V., Suh B.B., Kooij T.W., Pertea M., Silva J.C., Ermolaeva M.D., Allen J.E., Selengut J.D., KoO H.L., Peterson J.D., Pop M., Kosack D.S., Shumway M.F., Bidwell S.L., Shallom S.J., Van Aken S.E., Riedmuller S.B., Feldblyum T.V., Cho J.K., Quackenbush J., Sedegah M., Shoaibi A., Cummings L.M., Florens L., Yates J.R., III, Raine J.D., Sinden R.E., Harris M.A., Cunningham D.A., Preiser P.R., Bergman L.W., Vaidya A.B., van Lin L.H., Janse C.J., Waters A.P., Smith H.O., White O.R., SalzberG S.L., Venter J.C., Fraser C.M., Hoffman S.L., Gardner M.J. \& Carucci D.J. Genome sequence and comparative analysis of the model rodent malaria parasite Plasmodium yoelii yoelii. Nature, 2002, 419, 512-519.

DoOlan D.L. \& HofFMan S.L. The complexity of protective immunity against liver-stage malaria. Journal of Immuno$\log y, 2000,165,1453-1462$.

Douradinha B., van Dijk M.R., Ataide R., VAn GEMERT G.J., Thompson J., Franetich J.F., Mazier D., Luty A.J., Sauer- 
wein R., Janse C.J., Waters A.P. \& Mota M.M. Genetically attenuated P36p-deficient Plasmodium berghei sporozoites confer long-lasting and partial cross-species protection. International Journal for Parasitology, 2007, 37, 15111519.

Druilhe P., Renia L. \& Fidock D.A. Immunity to Liver stages, in: Malaria: Parasite Biology, Pathogenesis, and Protection, Sherman I.W. (ed) pp. ASM Press, Washington, DC, 1998, 513-543.

Florens L., Washburn M.P., Raine J.D., Anthony R.M., Grainger M., Haynes J.D., Moch J.K., Muster N., Sacci J.B. Jr, Tabb D.L., Witney A.A., Wolters D., Wu Y., Gardner M.J., Holder A.A., Sinden R.E., Yates J.R., III \& Carucci D.J. A proteomic view of the Plasmodium falciparum life cycle. Nature, 2002, 419, 520-526.

Gardner M.J., Hall N., Fung E., White O., Berriman M., Hyman R.W., Carlton J.M.R., Pain A., Nelson K.E., Bowman S., Paulsen I.T., James K., Eisen J.A., Rutherford K., Salzberg S.L., Craig A., Kyes S.A., Chan M.S., Nene V., Shallom S.J., Suh B., Peterson J., Angiuoli S., Pertea M., Allen J., Selengut J., Haft D., Mather M.W., Vaidya A.B., Martin D.M., Fairlamb A.H., Fraunholz M.J., RoOs D.S., Ralph S.A., McFadden G.I., Cummings L.M., Subramanian G.M., Mungall C., Venter J.C., Carucci D.J., Hoffman S.L., Newbold C.I., Davis R.W., Fraser C.M. \& Barrell B. Genome sequence of the human malaria parasite Plasmodium falciparum. Nature, 2002, 419, 498-511.

Hoffman S.L., Goh L.M., Luke T.C., Schneider I., Le T.P., Doolan D.L., Sacci J.B., Jr., De la Vega P., Dowler M., Paul C., Gordon D.M., Stoute J.A., Church L.W., Sedegah M., Heppner D.G., Jr, Ballou W.R. \& Richie T.L. Protection of humans against malaria by immunization with radiation-attenuated Plasmodium falciparum sporozoites. Journal of Infectious Diseases, 2002, 185, 1155-1164.

Jobe O., Lumsden J., Mueller A.K., Williams J., Silva-Rivera H., Kappe S.H., Schwenk R.J., Matuschewski K. \& KrZych U. Genetically attenuated Plasmodium berghei liver stages induce sterile protracted protection that is mediated by major histocompatibility complex class I-dependent interferon- gamma -producing CD8 ${ }^{+} \mathrm{T}$ cells. Journal of Infectious Diseases, 2007, 196, 599-607.

Kaiser K., Matuschewski K., Camargo N., Ross J. \& Kappe S.H. Differential transcriptome profiling identifies Plasmodium genes encoding pre-erythrocytic stage-specific proteins. Molecular Microbiology 2004, 51, 1221-1232.

Kappe S.H., Gardner M.J., Brown S.M., Ross J., MatuschewSki K., Ribeiro J.M., Adams J.H., Quackenbush J., Cho J., Carucci D.J., Hoffman S.L. \& Nussenzweig V. Exploring the transcriptome of the malaria sporozoite stage. Proceedings of the National Academy of Sciences USA, 2001, 98, 98958900.

Kramer L.D. \& VANDERBERG J.P. Intramuscular immunization of mice irradiated Plasmodium berghei sporozoites. Enhancement of protection with albumin. American Journal of Tropical Medicine and Hygiene 1975, 24, 913-916.

Labaied M., Harupa A., Dumpit R.F., Coppens I., Mikolajczak S.A. \& Kappe S.H. Plasmodium yoelii Sporozoites with simultaneous deletion of P52 and P36 are completely attenuated and confer sterile immunity against infection. Infection and Immunity, 2007, 75, 3758-3706.
Legros F., Bouchaud O., Ancelle T., Arnaud A., Cojean S., Le Bras J., Danis M., Fontanet A. \& Durand R. Risk factors for imported fatal Plasmodium falciparum malaria, France, 1996-2003. Emerging Infectious Diseases, 2007, 13, 883-888.

LuKE T.C. \& HofFman S.L. Rationale and plans for developing a non-replicating, metabolically active, radiation-attenuated Plasmodium falciparum sporozoite vaccine. Journal of Experimental Biology, 2003, 2006, 3803-3908.

Mellouk S., Lunel F., Sedegah M., Beaudoin R.L. \& Druilhe P. Protection against malaria induced by irradiated sporozoites. Lancet, 1990, 335, 721.

Molyneux D.H. Control of human parasitic diseases: context and overview. Advances in Parasitology, 2006, 61, 1-45.

Mueller A.K., Camargo N., Kaiser K., Andorfer C., Frevert U., Matuschewski K. \& Kappe S.H. Plasmodium liver stage developmental arrest by depletion of a protein at the parasite-host interface. Proceedings of the National Academy of Sciences USA, 2005, 102, 3022-3027.

Mueller A.K., Labaied M., Kappe S.H. \& MatuschewsKi K., Genetically modified Plasmodium parasites as a protective experimental malaria vaccine. Nature, 2005, 433, 164-167.

Mueller A.K., Deckert M., Heiss K., Goetz K., Matuschewski K. \& SCHLuTER D. Genetically attenuated Plasmodium berghei liver stages persist and elicit sterile protection primarily via CD8 T Cells. American Journal of Pathology, 2007, 171, 107-115.

Nussenzweig R.S., Vanderberg J.P., Most H. \& Orton C.G. Specificity of protective immunity produced by X-irradiated Plasmodium berghei sporozoites. Nature, 1969, 222, 488-489.

NusSENZWEIG R.S. Use of radiation-attenuated sporozoites in the immunoprophylaxis of malaria. International Journal of Nuclear Medicine and Biology, 1980, 7, 89-96.

Orjih A.U., Cochrane A.H. \& Nussenzweig R.S. Comparative studies on the immunogenicity of infective and attenuated sporozoites of Plasmodium berghei. Transactions of the Royal Society of Tropical Medicine and Hygiene, 1982, 76, 57-61.

Rénia L., Rodrigues M.M. \& Nussenzweig V. Intrasplenic immunization with infected hepatocytes: a mouse model for studying protective immunity against malaria pre-erythrocytic stage. Immunology, 1994, 82, 164-168.

Rénia L., Gruner A.C., Mauduit M. \& Snounou G. Vaccination against malaria with live parasites. Expert Review of Vaccines, 2006, 5, 473-481.

Rosenberg R.L. Ejection of malaria sporozoites by feeding mosquitoes. Transactions of the Royal Society of Tropical Medicine and Hygiene, 1992, 86, 109.

Russell P.F., Mulligan H.W. \& Mohan B.N. Active immunization of fowls against sporozoites but not trophozoites of Plasmodium gallinaceum by injections of homologous sporozoites. Journal of the National Institute of India, 1942, 4, 311-319.

Silvie O., Semblat J.P., Franetich J.F., Hannoun L., Eling W.M.C. \& MAZIER D. Effects of irradiation on Plasmodium falciparum sporozoite hepatic development: implications for the design of pre-erythrocytic malaria vaccines. Parasite Immunology, 2002, 24, 221-223. 
SCHELler L.F. \& AZAD A.F. Maintenance of protective immunity against malaria by persistent hepatic parasites derived from irradiated sporozoites. Proceedings of the National Academy of Sciences USA, 1995, 92, 4066-4068.

Snounou G., Gruner A.C., Muller-Graf C.D., Mazier D. \& RÉNIA L. The Plasmodium sporozoite survives RTS,S vaccination. Trends in Parasitology, 2005, 21, 456-461.

Spitalny G.L. \& NussenZweIG R.S. Effect of various routes of immunization and methods of parasite attenuation on the development of protection against sporozoite-induced rodent malaria. Proceedings of the Helminthological Society (Washington, DC), 1972, 39, 506-514.

Suhrbier A.S., Winger L.A., Castellano E. \& Sinden R.E. Survival and antigenic profile of irradiated malarial sporozoites in infected liver cells. Infection and Immunity, 1990, 58, 2834-2839.

Tarun A.S., Dumpit R.F., Camargo N., Labaied M., Liu P., TAKagi A., Wang R. \& Kappe S.H. Protracted sterile protection with Plasmodium yoelii pre-erythrocytic genetically attenuated parasite malaria vaccines is independent of significant liver-stage persistence and its mediated by CD8+ T cells. Journal of Infectious Diseases, 2007, 196, 608616.

van Dijk M.R., Douradinha B., Franke-Fayard B., Heussler V., van Dooren M.W., van S.B., van Gemert G.J., Sauerwein R.W., Mota M.M., Waters A.P. \& Janse C.J. Genetically attenuated, P36p-deficient malarial sporozoites induce protective immunity and apoptosis of infected liver cells. Proceedings of the National Academy of Sciences USA, 2005, 102, 12194-12199. 